\title{
Starch branching enzymes as putative determinants of postharvest quality in horticultural crops
}

Jingwei $\mathrm{Yu}^{1,2,3}$, Keyun Wang ${ }^{1}$ and Diane M. Beckles ${ }^{1 *}$ (D)

\begin{abstract}
Starch branching enzymes (SBEs) are key determinants of the structure and amount of the starch in plant organs, and as such, they have the capacity to influence plant growth, developmental, and fitness processes, and in addition, the industrial end-use of starch. However, little is known about the role of SBEs in determining starch structure-function relations in economically important horticultural crops such as fruit and leafy greens, many of which accumulate starch transiently. Further, a full understanding of the biological function of these types of starches is lacking. Because of this gap in knowledge, this minireview aims to provide an overview of SBEs in horticultural crops, to investigate the potential role of starch in determining postharvest quality. A systematic examination of SBE sequences in 43 diverse horticultural species, identified SBE1, 2 and 3 isoforms in all species examined except apple, olive, and Brassicaceae, which lacked SBE1, but had a duplicated SBE2. Among our findings after a comprehensive and critical review of published data, was that as apple, banana, and tomato fruits ripens, the ratio of the highly digestible amylopectin component of starch increases relative to the more digestion-resistant amylose fraction, with parallel increases in SBE2 transcription, fruit sugar content, and decreases in starch. It is tempting to speculate that during the ripening of these fruit when starch degradation occurs, there are rearrangements made to the structure of starch possibly via branching enzymes to increase starch digestibility to sugars. We propose that based on the known action of SBEs, and these observations, SBEs may affect produce quality, and shelf-life directly through starch accumulation, and indirectly, by altering sugar availability. Further studies where SBE activity is fine-tuned in these crops, can enrich our understanding of the role of starch across species and may improve horticulture postharvest quality.
\end{abstract}

Keywords: Starch branching enzyme, Horticultural crops, Postharvest quality, Postharvest shelf-life

\section{Background}

Horticulture likely originated 20,000 years ago [1]. There are over 100 species of horticultural crops [2], consisting of diverse fruits, vegetables, and tubers [3], many of which are of high economic value with enormous production volume worldwide [4]. The amounts of fruits, vegetables, and tubers produced in 2018 were 868,1089 ,

\footnotetext{
*Correspondence: dmbeckles@ucdavis.edu

1 Department of Plant Sciences, University of California, One Shields

Avenue, Davis, CA 95616, USA

Full list of author information is available at the end of the article
}

and 832 million tons respectively (FAO, 2019), and the increased demand from a growing, and affluent global population, is predicted to drive further expansion of horticultural output $[5,6]$. Horticultural crops not only provide basic calories (e.g., tubers and roots), but also, are among the most crucial sources of fiber, organic acids, micro- and macro minerals, vitamins, and antioxidants in human diets $[7,8]$. Healthy attributes, and a wide range of tastes, textures, and flavors make horticultural crops attractive [5].

Starch is critical to human society given its versatile uses [9]. Starch is the dominant energy source in the 
human diet, providing over $50 \%$ of our daily caloric needs [10]. In the food industry, starch is widely used as a thickener, stabilizer, lipid replacer, defoaming agent, gelling agent, emulsifier, and dietary fiber, and in the pharmaceutical industry, starch is used as an excipient for drug delivery [11-13]. In addition to these diverse uses, starch is an excellent renewable material for making ethanol biofuels and degradable 'bioplastic' products [14].

Starch is almost ubiquitous in higher plants [10, 15], including horticultural crops, in ways that may or may not be noticed. For instance, potato, sweet potato, yam, and cassava are starchy, but spinach, lettuce, and ripe tomatoes, berries, and citrus are not, yet starch is likely to be important to the growth, development and fitness of all of these crops, as they are in better studied models [16-19].

The widely accepted view is that starch accumulates either in a transitory state, or for long-term storage starch [20]. Transitory starch follows a diurnal pattern: it is synthesized and accumulated directly from the products of photosynthesis in the leaf and in the stem during the daytime, and is then degraded into sugars as an energy source for the following night [21]. In comparison, storage starch is defined as that located in perennating organs such as seeds, grain, embryos and tubers $[15,22]$, where it provides sustenance for the next generation during germination and sprouting in sexual and asexual propagated crops, respectively [23]. A third class of starch: 'transitory-storage starch' has been proposed [24, 25]. It describes starch that is accumulated and degraded during development in the storage organ $[24,25]$. Transitory-storage starch is a feature of many species including horticultural crops of economic value such as tomato, banana, kiwi, strawberry, nectarine, and apple fruit [26, 27].

Starch accumulates as semi-crystalline, water insoluble granules that vary in diameter from 1 to $100 \mu \mathrm{m}$ depending on species [15]. Starch is organized into two glucan polymers: amylose and amylopectin [28]. Amylose and amylopectin consist primarily of linear chains of glucoses joined by $\alpha-1,4$-glycosidic bonds [29]. In amylopectin, the $\alpha-1,4$-glucan chains are branched more frequently $(\sim 5 \%$ of the linear chains) through $\alpha-1,6$-glycosidic bonds, compared to amylose [29]. The branching of the amylopectin chains is such that chains of different lengths are produced: short, medium and long chains, and the frequency with which each fraction occurs influences starch functionality [30]. Side chains of amylopectin form clusters around branching points, and two adjacent chains make up a double helix [31]. These physical features of amylopectin polymers leads to a semi-crystalline granule; amylose with a randomly coiled conformation, fills the matrices within the granule [32]. Amylopectin and amylose account for around 25 and $75 \%$ of the starch in major heterotrophic storage organs, respectively [33], while the starch in leaf tissues is approximately $5-10 \%$ amylose [34].

\section{Main text}

Amylose and amylopectin are synthesized by the coordinate action of a group of four key enzymes [35]. The core starch biosynthetic enzymes include ADP-glucose pyrophosphorylases (AGPases), starch synthases (SSs, granule bound or soluble), starch branching enzymes (SBEs), and de-branching enzymes (DBEs), of which there are many isoforms [36]. In brief, AGPases initiate the first step of starch biosynthesis by catalyzing the formation of ADP-glucose [37, 38]. SSs elongate the glucan chains in amylose and amylopectin [39]; SBEs branch the glucan chains [40], while the DBEs shorten and modify the starch chains which enable a higher-order semicrystalline structure to form [41]. SBEs, the focus of this review, hydrolyze $\alpha-1,4$-linked glucan chains, and attach the newly-created 'free' chain to another glucan chain within the starch granule, via an $\alpha$-1,6-linkage (Figure S1) [42]. Through this action, SBEs largely determine the proportion of the relatively unbranched amylose to the highly-branched amylopectin [40, 43, 44].

Two major classes of SBEs are biofunctionally known: SBE1 and SBE2 (Table 1), and they vary in terms of their substrate selectivity [40], whereas the function of SBE3 awaits verification across a broader set of species. SBE1 preferentially branches 'amylose-like' long glucan chains as the substrate, while SBE2 prefers a more branched substrate [10]. The action of both forms further increases the number of branch points in starch polymers [40].

SBEs are the key players in the regulation of the amylose-to-amylopectin proportion in plants. However, their functions in many harvested horticultural crops have been under-investigated, although evidence points to the importance of starch in determining the postharvest quality of these crops. We aimed to develop a better understanding of the role of SBEs in fruits, tubers, and leafy greens in physiological processes by exploring SBE sequence relationships, expression, and starch phenotypes in diverse crops.

\section{Cereal SBEs diverge from the majority of horticultural SBEs} SBEs have three classes of isozymes including two functional SBE classes (SBE1 and SBE2) and one putative class 3 SBE (Fig. 1A). SBE1 isoforms appeared earlier than SBE2 and SBE3 in the viridiplantae, but plant SBE1 and SBE2 are more homologous to each other, than to SBE3 [45-47]. SBEs have been identified and relatively well-characterized in cereal crops, tubers, and Arabidopsis thaliana over the last two decades [48-51], 
Table 1 Examples of Starch Branching Enzyme (SBE) nomenclature

\begin{tabular}{lllll}
\hline Species & Names used in this paper & Other names reported & Class & Locus tag/Gene symbol \\
\hline Maize (Z. mays) & SBE1 & SBEI & 1 & LOC542315 \\
& SBE2a & SBElla & 2 & LOC542342 \\
& SBE2b & SBEllb & 2 & LOC542238 \\
Potato (S. tuberosum) & SBE1 & SBEB & 1 & LOC102596498 \\
& SBE2 & SBEA & 2 & LOC102590711 \\
& SBE3 & SBE3 & 3 & LOC102603708 \\
Arabidopsis thaliana & SBE3 & BE1 & 3 & AT2G36390 \\
& SBE2.1 & BE3/BE2.1 & 2 & AT5G03650 \\
\hline
\end{tabular}

but, as mentioned, little attention has been paid to the diverse group of species that are classified as horticultural crops.

Within each class of SBE, the cereals grouped together, while most non-cereals formed another cluster (Fig. 1A). This pattern is due to the divergence of monocots from dicots around 200 million years ago [46]. In contrast to the presence of 'a' and 'b' sub-isoforms of SBE2 in cereal crops [63], horticultural plant species generally have one SBE2 isoform. It was also observed that not all species have a known or predicted class 3 isoform.

The SBE sequences contained within diverse organs, i.e., fruits, tubers, roots, and leafy vegetables (Fig. 1B), clustered together based on their respective plant families. The class $1 \mathrm{SBE}$ is absent in Arabidopsis thaliana [28], and so it was not surprising that this SBE class is not present in the Brassicaceae. However, the class 1 SBE is also absent in apple (Malus), and European olive (Olea), but these species all have two class 2 SBE isoforms (Fig. 1B). In addition, banana contains at least four types of SBE2, and transcripts corresponding to these
SBE2s have been identified, indicating that they are expressed [64].

\section{The domain features of SBE1 and SBE2 are highly conserved while those of SBE3 are not}

Starch Branching Enzymes (E.C. 2.4.1.18) belong to the $\alpha$-amylase family of enzymes, specifically the glycoside hydrolase family 13 superfamily $[65,66]$, with multiple isoforms encoded by different genes (Figure S2). The overall structure of the SBE polypeptide is highly conserved [67]: all SBEs possess a central $\alpha$-amylase catalytic domain (the A domain), and an $\mathrm{NH}_{2}$ - terminus, and a carboxyl-terminus (Fig. 2, S3) [68, 69].

The SBE NH2-terminus contains two conserved domains: a chloroplast transit peptide for plastid-targeting, and a CBM48 (carbohydrate-binding module 48) domain for binding to starch [71]. The C-terminus contains the residues that determine substrate preference and catalytic activity [40]. The central region of the enzyme contains the " $\mathrm{A}$ " catalytic domain, that is made up of $8-(\beta / \alpha)$-barrels [68]. Notably, the class 3 SBE may not directly participate in starch biosynthesis in Arabidopsis

\footnotetext{
(See figure on next page.)

Fig. 1 The three starch branching enzymes (SBEs) clades. A) A phylogenetic tree based on SBE DNA sequences from cereal and horticultural crops. The three clades correspond to the three classes of SBE, i.e., SBE1, SBE2, and SBE3. Cereals and horticultural crops diverged in each class. Within the class 2 SBEs, cereals form two clades, representing the 'a' and 'b' sub-isoforms (See Table 1). Only a few members of the predicted SBE3s were retrieved from cereals. This tree includes species from: rice, wheat, barley, sorghum, corn, millet, apple, banana, blueberry, rapeseed, cabbage, bok choy, citruses, cucumber, wax gourd, muskmelon, watermelon, pumpkins, date palm, durian, apricot, jujube, kiwifruit, lettuce, olive, papaya, peach, pear, pineapple, tomato, potato, pepper, eggplant, spinach, strawberry, sweet cherry, carrot, cassava, lotus root, radish, sweet potato, taro, and table grapes. B) A phylogenetic tree based on the predicted amino acid sequence of various SBE genes identified from horticultural crops showing sequence divergence. SBE1 evolved earlier than SBE2 and SBE3. SBE1 and SBE2 are more homologous to each other than to SBE3. SBEs from fruits, tuber \& root, and leafy green were highlighted accordingly. SBE1 is absent in crops from the Brassicaceae family, apple, and European olive, while these species have two types of SBE2. Species presented include apple, banana, blueberry, rapeseed, wild cabbage, mustard, citruses, cucumber, wax gourd, muskmelon, watermelon, pumpkins, date palm, durian, apricot, jujube, kiwifruit, lettuce, olive, papaya, peach, pear, pineapple, tomato, potato, pepper, eggplant, spinach, strawberry, sweet cherry, carrot, cassava, lotus root, radish, sweet potato, taro, and table grapes. Sequences were retrieved from NCBI, Mainlab Bioinformatics Program (WSU) [52, 53] Sol Genomics Network [54], Genome Database for Vaccinium [55], CuGenDB [56, 57], Pineapple Genomics Database [58, 59] SpinachBase [60], KEGG [61], and Ensembl plants [62]. This tree was built by using the Neighbor-joining method with genetic distance (Jukes-Cantor Model) in the Geneious Prime ${ }^{\circledR}$ (Version 2020.2, https://www.geneious.com). The bootstrap test was performed with 1000 replicates. The figure generated was annotated using Microsoft ${ }^{\circledR}$ PowerPoint
} 

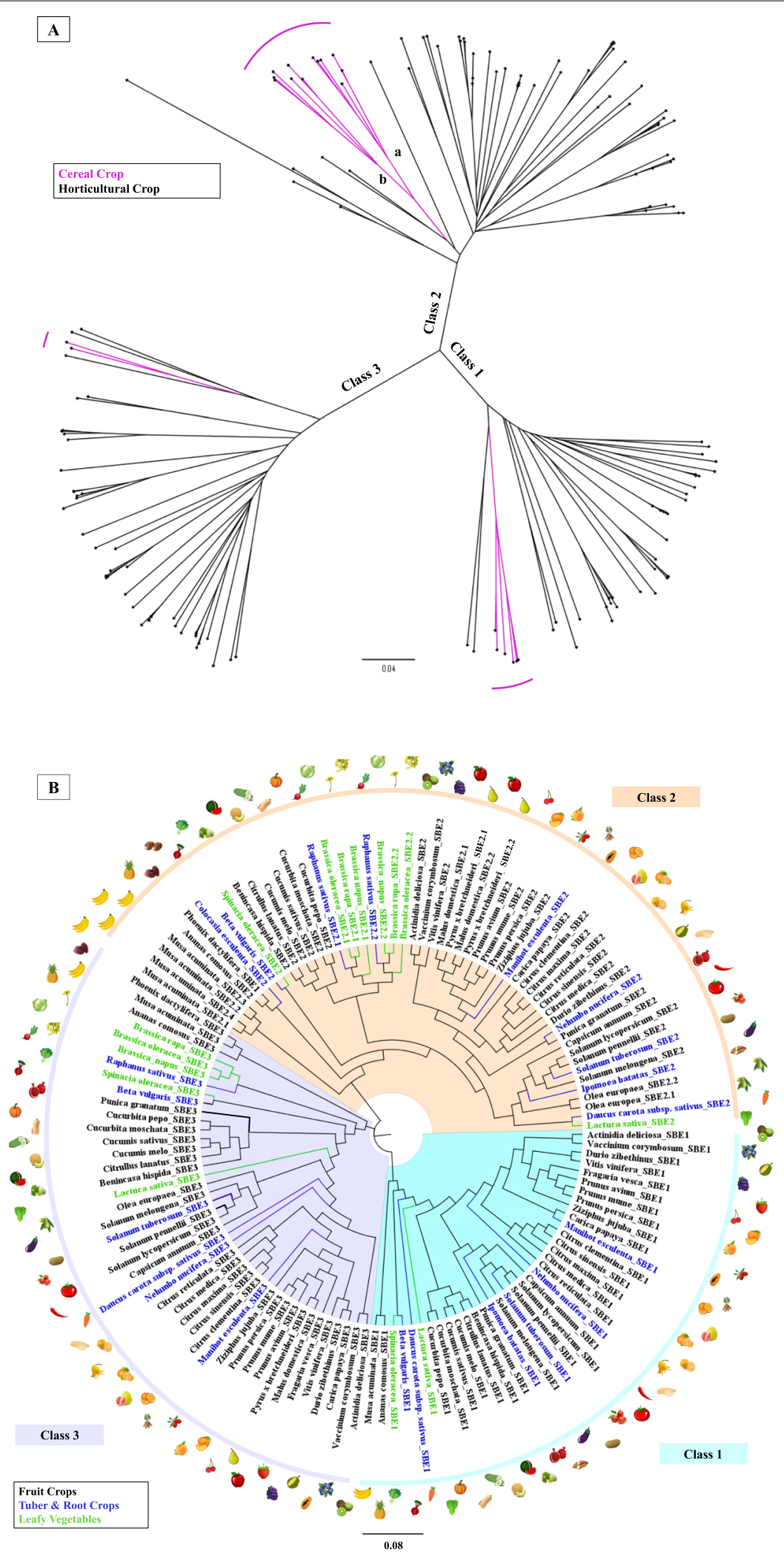

Fig. 1 (See legend on previous page.) 


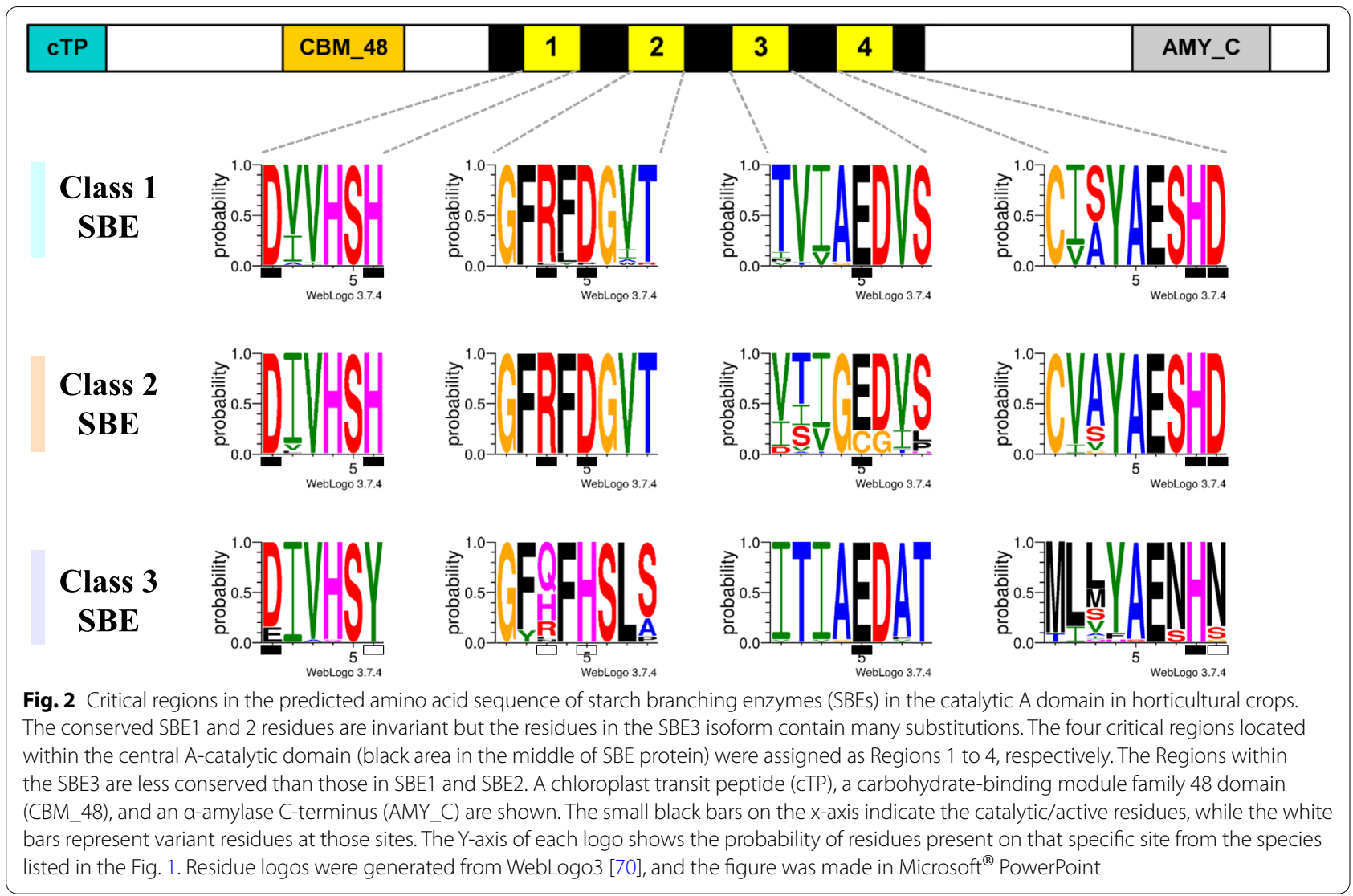

$[49,72]$, but it has a demonstrated function in mediating cesium toxicity of photosynthesis [73]. However, the role of SBE3 is unlikely to be conserved. In potato, StSBE3 has a unique coiled-coil motif which is absent in the AtSBE3 polypeptide (Figure S3). Notably, the CBM48 domain is also deficient in AtSBE3 (Figure S3). It is possible that the StSBE3 may interact and complex with other starch biosynthetic enzymes through its coiled-coil domain, in a similar way to the SS4-PTST2 interaction in Arabidopsis [74], the GBSS-PTST1 interaction in rice [75] or the SBEcontaining protein complexes in cereal endosperm [76], rendering an assistant function in starch biosynthesis. This species-specific mode of action of SBE3 may reveal a novel function of SBEs generally. Indeed, although all SBEs are predicted to form complexes with starch phosphorylases (PHO1 and PHO2), the starch synthases (GBSS, SS1 or SS4) and isoamylase (ISA) (Table S2; Figure S5), interactions with other proteins show differences depending on the species and SBE isoform.

\section{The SBE3 group lacks the conserved residues} in the A-domain critical for catalysis

Four conserved regions critical for catalysis, named Regions 1-4 (Fig. 2), are found within the catalytic
A-domain (reviewed by Tetlow and Emes [40]). Regions 1-3 are directly involved in catalysis, while Region 4 is involved in direct substrate binding (Fig. 2) [67]. SBE1 and 2 have largely invariant residues, but the residues in the SBE3 isoform of many species have substitutions at these sites. Post-transcriptional phosphorylation of the SBE-protein complexes formed with other starch biosynthetic enzymes has been found in cereal crops and in cassava [76-79], while experimental evidence of this regulation in the majority of horticultural crops is absent. SBE1 and SBE3 have fewer possible phosphorylation amino acid sites than SBE2 (data not shown). Overall, the distinctive domain features of the SBE3 predicted protein, and the implifications for functionality may complicate current views of SBE function, but these features may also provide an opportunity to deepen our mechanistic understanding of starch biosynthesis and regulation.

The SBE gene family contains cis-elements that indicate gene activation by environmental signals and hormones Starch metabolism is tightly regulated by plants' internal clock and the external day-night shifts, especially in photosynthetic organs where transitory starch turnover 
occurs on a daily basis [80]. The transcriptional response of the SBE genes follows the circadian rhythm in photosynthetic, and, in some cases, storage tissues [81]. Cis-elements related to circadian control and light responsiveness were universally present in all the horticultural SBEs examined (Figure S4). Hormones, such as abscisic acid (ABA), ethylene, salicylic acid (SA), jasmonic acid (MeJA), and sugar signals have been reported to regulate SBE activity in cereal and horticulture crops [81-83]. In addition, transcription factors (TFs) that belong to the WRKY, MYB, bZIP, AP2/EREBP families, may bind to their cognate cis-elements in the $5^{\prime}$ upstream regions of SBEs to activate or suppress transcription [64, 84-86]. However, information on the transcriptional regulations of SBE is fragmented, and putative hub genes or master regulators have not been identified [87]. Systemwide surveys of cis-elements and TFs in combination with in vitro and in vivo experiments could shed light on, and unearth such regulatory networks.

\section{Amylose-to-amylopectin ratio in horticultural starches: end-use and functionality}

The amylose-to-amylopectin ratio influences the textural, cooking, and nutritional properties of starchy foods, and the functionality of starch-derived biomaterials [9, 88-92]. Most of this structure-function analysis has been performed on starches isolated from cereals and tubers [32]. However, the relative proportions, and molecular structure of amylose and amylopectin in unripe fruit may have unique properties that could have specialized applications distinct from these well-characterized starches [93]. There may be additional markets for fruit starches if premature harvest occurs, or is desirable, due to climactic events [24].

Starch, or the proportion of the amylose fraction of starch, is used as a common ripening biomarker for apple [94], banana [95, 96], and pear [97]. This marker relies on the ability of amylose to physically interact with iodide to form a triiodide blue-black complex.

Starch can also influence the quality of fruit juice. Although starch is degraded to sugars when fruit ripens, this conversion is not complete. Ripe fruit processed for juice therefore contains starch, which is treated with amylases for clarification [98]. Further, the amylose content of the remanant starch in some fruit processed for juice, may alter juice viscosity [99].

\section{Putative role of SBEs as determinants of postharvest quality in horticultural crops} Deducing SBE function in leafy greens using Arabidopsis rosettes as a model

Prepackaged leafy greens are convenient and healthy, and are popular options for salads in western countries
$[5,100]$. Metabolism in this horticultural product can be considered over distinct phases in its lifecycle: pre- and postharvest [101]. In developing spinach, the photosynthetic organ, i.e., the leaf, fixes carbon, and partitions a large portion $\sim 20 \%$ to starch biosynthesis during the light period under lab conditions [102]. Starch accumulates linearly across the daytime at an almost constant rate (paralleling an increase in sugar content) (Fig. 3). During the night, the leaf starch is degraded into sugar, to maintain plant metabolism, resulting in an empty polysaccharide reserve before the next light period $[103,104]$. In Arabidopsis, the expression of SBEs and the changes of amylopectin and amylose (AP/AM) show a similar trend, but there is variation in when SBE transcripts peak. Although there is no information on SBE transcriptional levels in spinach during the diel, there may be some similarities with Arabidopsis because the pattern of leaf starch accumulation is comparable in spinach and Arabidopsis [105-108].

The preharvest starch reserve may alter the postharvest quality of leafy greens. Harvested green produce are stored in optimized packaging under limited light exposure conditions which restricts new energy and carbon input from photosynthesis (Fig. 4) [111-113]. However, respiratory activity, which is the carbon skeleton generation process for cellular metabolites, although reduced, does not stop [26]. In detached leaves, the starch can be broken down to glucose, and sugars become the main source of fuel for cellular metabolism and ATP generation in the early stage of respiration [111, 114, 115]. In the late stage of the respiratory process, the depleted sugars will be replaced by proteins, lipids, and membranes, triggering leaf senescence and cell death [26, 116]. This results in undesirable produce quality and ultimately, in produce loss [5]. Preharvest and postharvest starch content may determine postharvest energy reserves and influence the timespan that buffers the onset of senescence, thus influencing shelf-life of harvested green leaves [114, 117, 118]. Correlations between leaf starch content and postharvest longevity have been found. For example, lettuce and red chard harvested at the end of the day, when leaf starch content was highest, had a longer extended shelf-life than organs harvested at other times of day $[114,117,118]$. This may not be true of all varieties e.g., salad roquette [117]. Starch also correlated with improved shelf-life quality after light exposure to detached leaves in vegetables such as Chinese kale and lettuce [118-121]. The accessibility of sugars from the degraded starch may relate to leafy-green quality, and the upregulation of SBEs would convert amylose to the more catabolically available amylopectin, providing a more readily available source of sugar. 


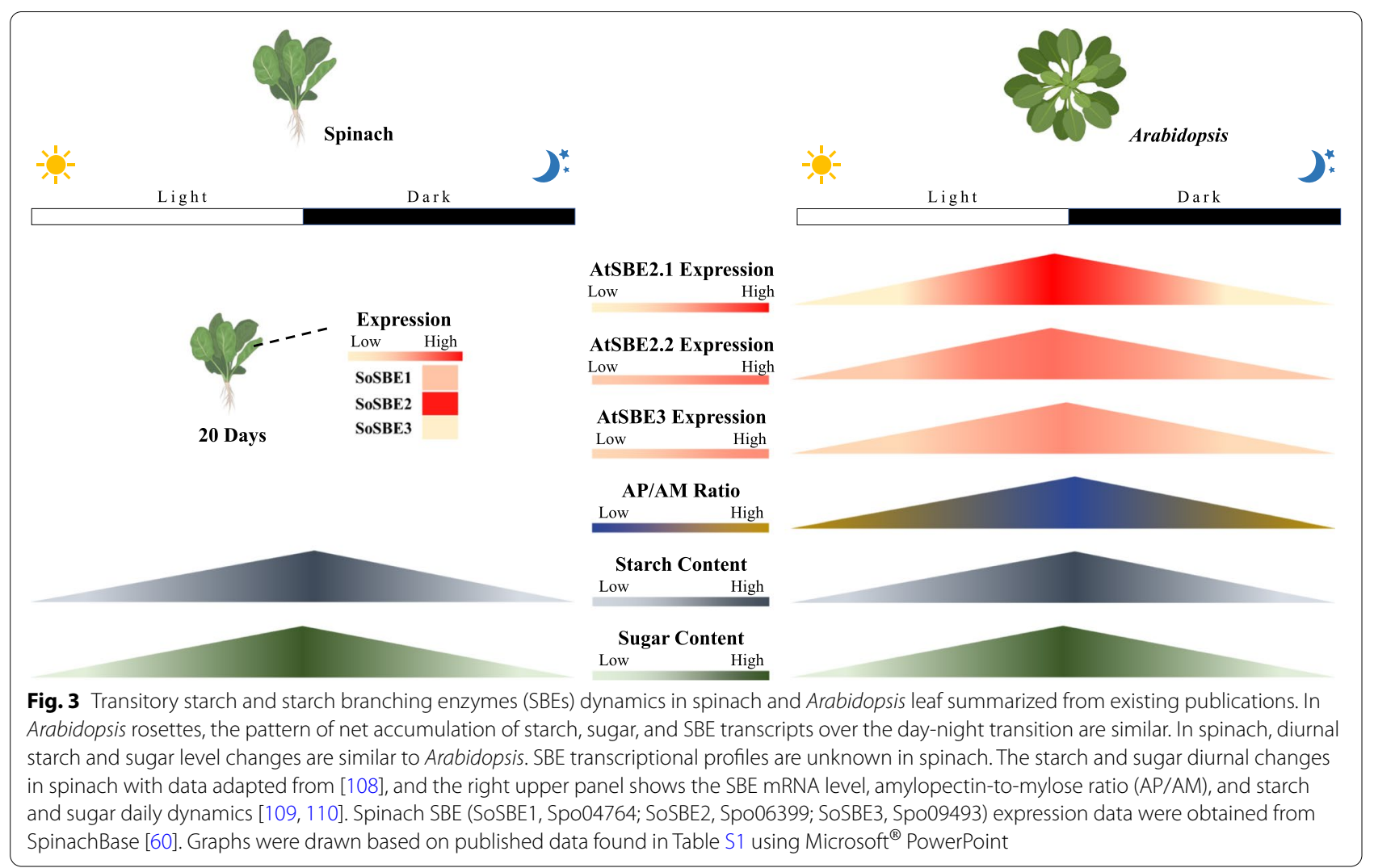

The amylose-to-amylopectin ratio in Arabidopsis influences flowering time and reproductive growth, key markers of development, and fitness [23, 124, 125]. Whether starch molecular structure and composition influences the preharvest growth of leafy greens in a similar way, remains unknown, but it seems likely.

\section{SBEs are determinants of potato and cassava postharvest tuber quality}

Potato, sweet potato, and cassava are generally considered as high glycemic index (GI) foods because the starch in their storage organs is easily digested to sugars when consumed, leading to a rapid increase in blood sugar level [126]. It is established that high GI food exacerbate metabolic disorders such as diabetes and obesity [127]. In contrast, multidisciplinary experimental research shows that digestion-resistant starch could increase the healthful microbial communities of the gastrointestinal tract, reducing the occurrence of constipation, and lowering the risk of colon cancer [90, 128]. Altering potato starch composition is a viable way to increase 'dietary fiber' content and to enhance colonic health. This can be achieved by either physical, chemical, or enzymatic modifications of purified starch, e.g., etherification, esterification, or by fine-tuning the activity of starch biosynthetic enzymes $[129,130]$. Reduction or knockout of SBEs in a range of species have reliably led to an increase in the resistant starch (RS) content in various species including horticultural crops e.g., potato, sweet potato, and cassava, [75, $78,130-140]$. Interestingly, SBE2 is not the dominant isoform expressed in storage tubers and roots, but it exerts a major function in amylopectin synthesis [141]. Very high levels of RS can be achieved by the combined suppression of SBE1 and SBE2, but with a yield penalty [142]. The transcriptional profiles and functions of SBE3 are unclear in the developing tubers (Fig. 5).

In addition, potato tubers suffer from a postharvest disorder: cold-induced sweetening (CIS). Potato tubers are stored at low temperatures $\left(<11^{\circ} \mathrm{C}\right)$ to extend shelflife and to meet year-round demand [145]. However, sugars accumulate from starch breakdown, a process referred to as CIS (Fig. 5) [148, 149]. Although a problem for the potato industry, CIS could be a mechanism to allow tubers to cope with chilling stress $[16,18]$. CIS negatively affects the quality of fried or baked potato products: reducing sugars react with free amino acids at high temperature cooking through the Maillard reaction, to form carcinogenic acrylamide [150, 151]. Changes in the enzymes involved in starch biosynthesis and degradation are involved in CIS [152]. SBEs are actively expressed in CIS susceptible tubers [147], and in StVInvsilenced, CIS-resistant tubers, SBEs transcriptional level 


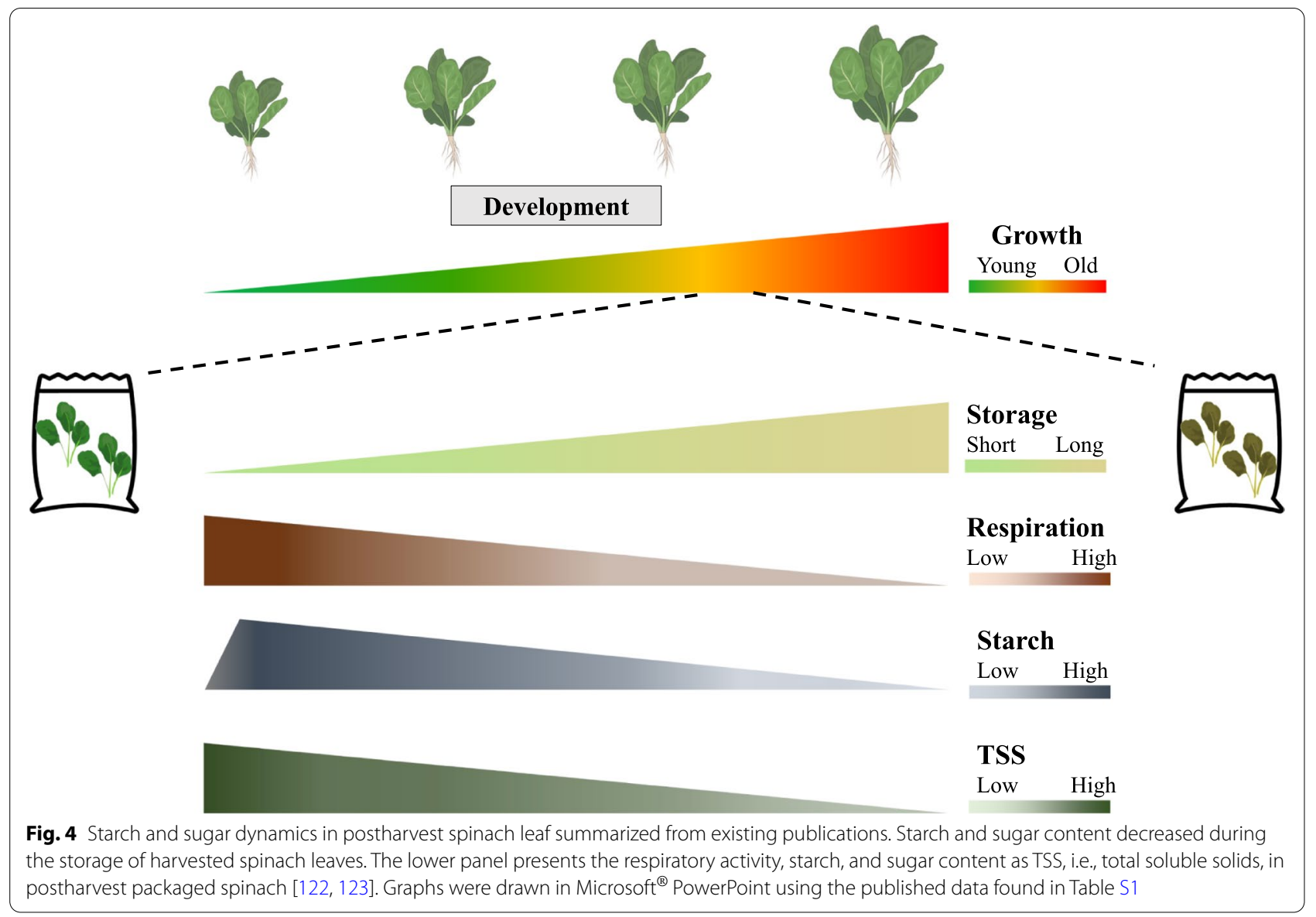

were suppressed [153]. Naturally occurring high RS potato varieties, also, have less susceptibility to CIS [154]. Therefore, evidence points to a positive association of SBE activity with CIS severity in some potato genotypes.

\section{Ignored 'transitory-storage starch' may contribute to fruit quality}

Starch is a major component of the dry mass of fruits at commercial harvesting time. Starch is transiently synthesized and stored in unripe fruits with a peak just before ripening [155]. Starch appears to be a critical feature of climacteric fruit metabolism, known for their bursts of respiratory activity and ethylene production upon ripening $[27,156]$. Climacteric fruits contain more starch, and, more active starch biosynthesis than nonclimacteric fruit after anthesis $[27,156]$. In tomato, the functional genomics model for fleshy climacteric fruit, starch fulfilled $40 \%$ of the carbon needed for respiratory processes based on a constraint-based flux model [157]. Experimental evidence from postharvest metabolism also supports the model: tomato fruits stored postharvest under low or chilling temperatures undergo bursts of stress-related carbon dioxide and ethylene production when allowed to recover at room temperature, with an accompanying and corresponding decrease in starch reserves $[158,159]$. A similar inverse relationship between starch content and respiratory activity was observed in ripening banana [96, 160-162], ginger rhizomes [163] sunberry [164], apple [165] and durian [166] (Figure S6; Table S3). The relationship between tissue starch content and respiration may not be perfectly linear in all species, e.g., in stored ginger, starch showed a biphasic accumulation pattern as respiration progressed, a trend not seen in other tissues examined (Figure S6; Table S3). Furthermore, the relationship between these variables may also differ among genotypes within a species.

Apart from climacteric characteristics, after the onset of ripening, starch content plummets sharply accompanied by starch decomposition into soluble sugars, and the total soluble sugar content continues to rise proportionally (Fig. 6). This dynamic metabolic process had been reported for both climacteric and non-climacteric species including tomato, apple, banana, plantain, mango, kiwifruit, pear, and strawberry [27, 97, 155, 167 169]. Adequate storage of the starch-derived soluble 


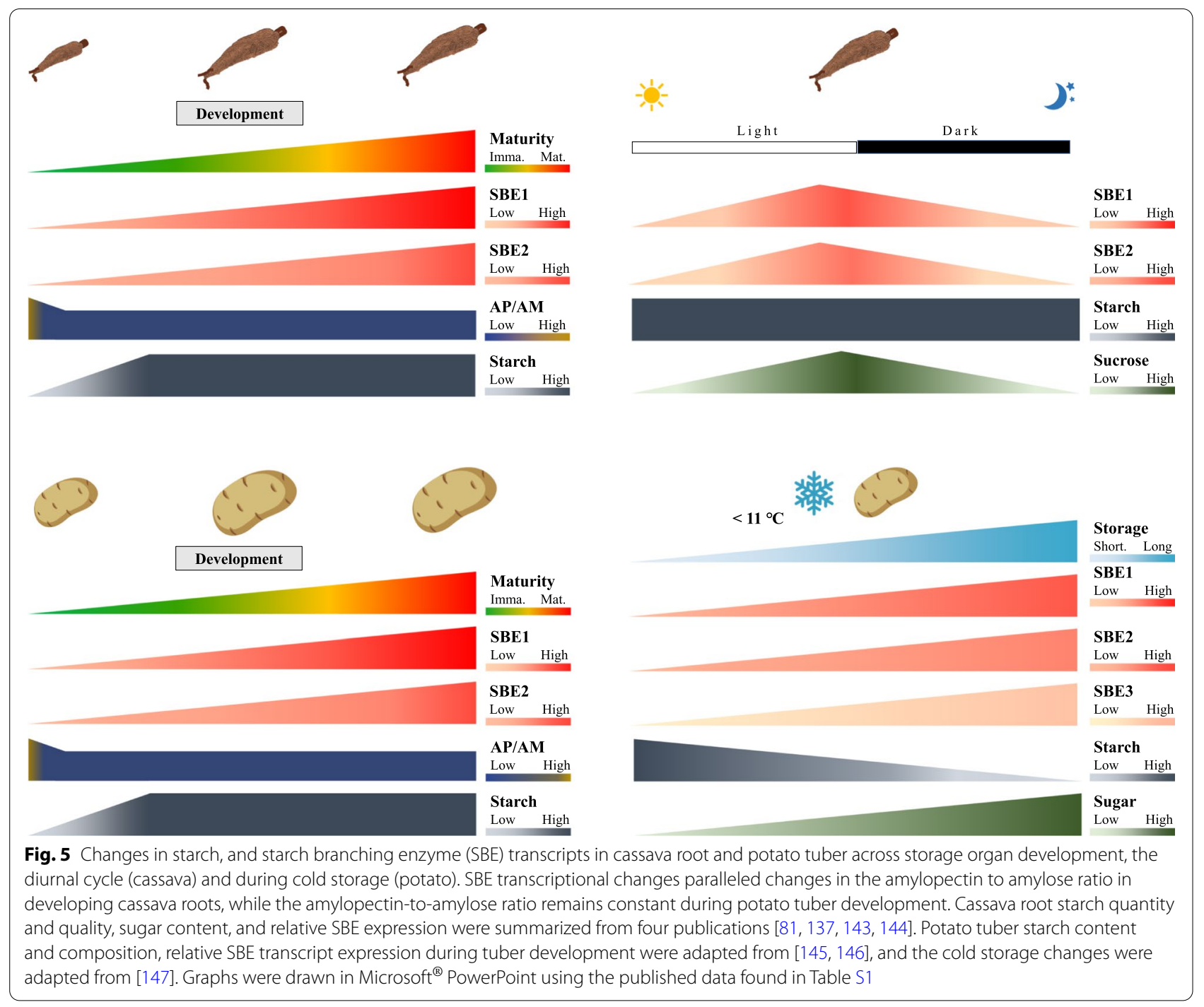

sugars, is essential to produce an acceptably flavored horticultural produce of appropriate sweetness [170].

Accompanying the starch-sugar dynamics, amylopectin-to-amylose ratio (AP/AM), also changes interactively (Fig. 6). The difference in the AP/AM ratio in fruit development is expected to influence the structure of starch and its degradability. In the ripening tomato, the rate of decrease of amylose was greater than that for amylopectin [169]. Thus, the AP/AM ratio increased dramatically during ripening, in concert with the increase in soluble sugar content and fruit color change from green to red [169]. This phenomenon where the proportion of amylopectin increases relative to amylose, was also evident in ripening apple and banana [64, 173]. It is possible to speculate that of the available starch left during fruit ripening, the amylose, or longchained amylopectin was converted into amylopectin whose branch-like structure has a much higher susceptibility to enzyme attack, allowing the rapid process of starch degradation into soluble sugars and supply for respiration. However, this mechanism may not be universal for all fruit. For example, the changes in AP/ AM ratio in kiwifruit are similar to those in developing potato tubers, where the ratio of $\mathrm{AP} / \mathrm{AM}$ almost remains constant during tuber development (Fig. 5) [155]. In ripening tomato fruit with sharp increases in AP/AM, up-regulation of SBEs transcriptional expression is expected. Among SBEs, the class 2 SBE has the major effect on altering starch compositions [40, 141]. Elevated expression of SBE2 transcripts does parallel the changes in the AP/AM in ripening tomato, apples, and banana. We propose that ultimately, this change in glucan structure indirectly contributes to flavor, quality, and commodity value. 


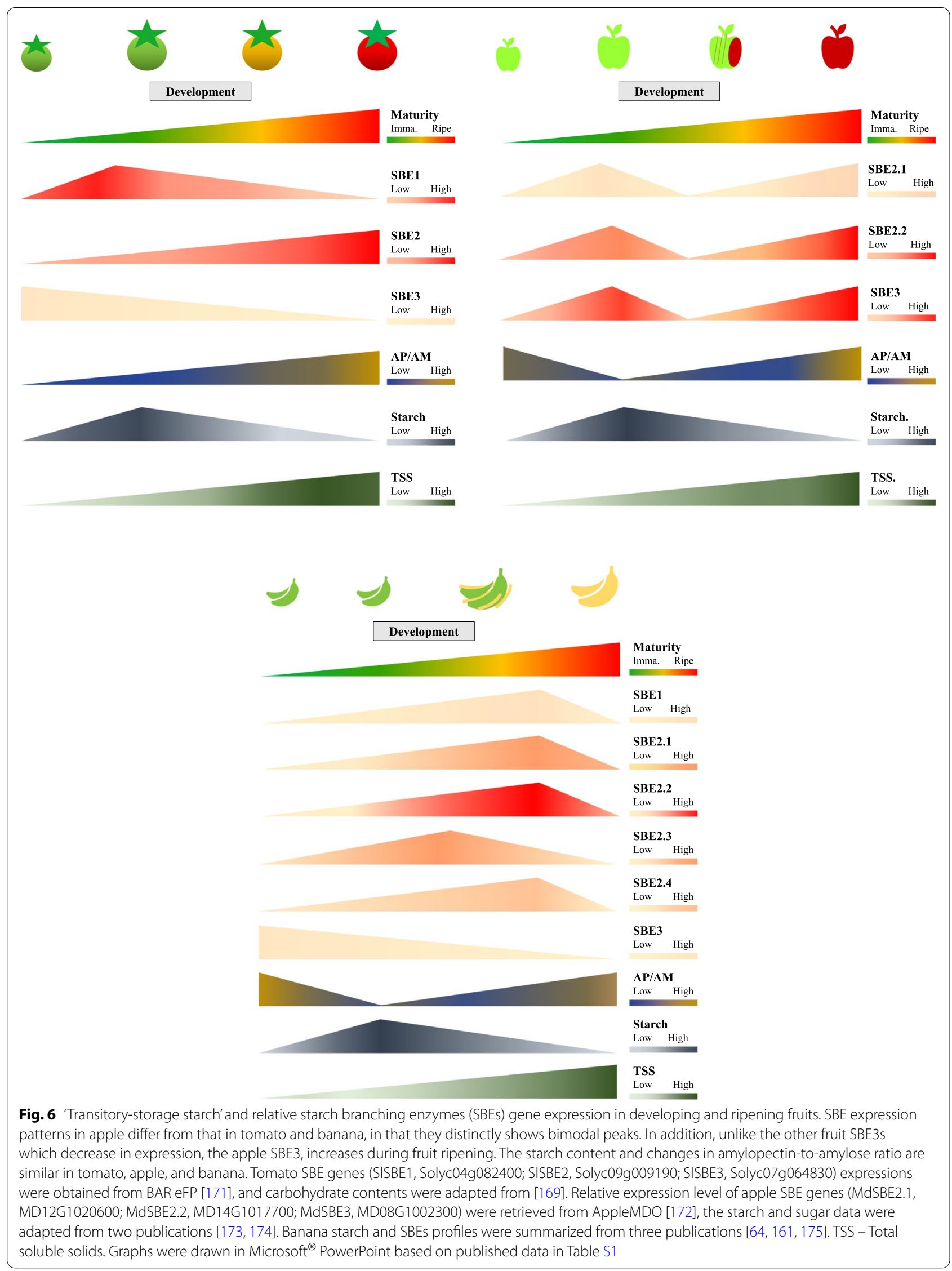




\section{Altering the postharvest quality of horticultural produce by modifying starch}

Starch, in general, plays an essential role in balancing the plant's carbon budget as a reserve of glucose that is tightly related to sucrose metabolism and sugar signaling pathways [23]. Starch is considered as an integrative mediator throughout the plant life cycle, regulating plant vegetative growth, reproductive growth, maturation and senescence, and response to abiotic stresses $[16,18,19]$. This comprehensive regulation is achieved by changes in the synthesis and degradation of starch to balance glucose levels, after developmental and environmental triggers in different organs [176].

Transitory starch and its biosynthesis have been well studied in the model plant Arabidopsis, but little research has been conducted on postharvest leafy greens. Quality metrics such as shelf-life, flavor, color, firmness, and texture are of consumers' choice, and they are related to the limited pools of storage compounds in detached leaves, which cells rely on to maintain basic cellular activities [26]. A hypothesized function for the starch in packaged leaves could be presented as such: starch may act as a buffer against sugar starvation, and protect against cellular autophagy, by serving as an alternative energy source [103]. If the biosynthesis and degradation of starch could be adjusted in a controlled way, then the modulated release of sugars may influence the postharvest shelf-life in detached leafy greens (Fig. 4). A continuous, paced supply of sugars may preserve vacuolar nutrients and water content, leaf cellular structure and integrity, and, thus extend the 'best by' postharvest date of the produce. Although the eco-physiological role of amylose is poorly understood in Arabidopsis [177], the AP/AM ratio may set a threshold for the optimum usage of starch. SBE action in leafy crops may differ from those in Arabidopsis given the dissimilar numbers of their isoforms and domain features (Figure S3). Modifying the quantity and quality of the starch in leafy greens such as spinach, lettuce, and watercress, by targeting starch biosynthetic enzymes, may provide evidence to its postharvest function in terms of produce longevity.

Resistant starch is a popular nutritional additive to produce food with enhanced quality attributes, i.e., higher fiber content, and starchy horticultural commodities are similarly attractive [128]. The yield penalty of high amylose crops may be alleviated by picking an ideal AP/AM ratio through a coordinate change in the relative balance of starch biosynthetic enzymes [44]. In the case of potato, it is plausible that downregulation of SBEs not only produces healthy fiber-starch, but also lessens the CIS severity and acrylamide problem (Fig. 5). However, the sugars derived from starch during CIS may be an adaptive mechanism to enhance plant chilling tolerance
$[16,18]$. Rapid sugar accumulation upon cold stress have been reported in fruit $[158,159,178]$. The sugars freed from starch may promote metabolic activity and serve as an osmoprotectant, thus alleviating chilling injury. The major functional SBEs were found to be upregulated in cold-stressed banana fruit, potato tuber, and Arabidopsis leaf [64], which may facilitate the 'sugaring' process. Modulating SBE activities may alter the rate of sugar released from the highly digestible starch polymers, thus changing the fruit/tuber cold responses.

In fruiting species, the importance of 'transitory-storage starch' may be underestimated due to the lack of enough direct knowledge of its function, gained from experimental data. Tomato serves as a functional genomics model for fleshy fruit, as it is easily transformed and genetically manipulated [179]. The putative function of 'transitory-storage starch' in fruit ripening, respiration, and sweetness enhancement may be revealed by engineering AP/AM ratio through overexpression or suppression of SBEs. We hypothesize that high amylose, resistant starch tomato fruit may have reduced available starch, sugars, and changes in fruit ripening and other processes that are dependent on starch as a carbon supply and source of energy postharvest. Tomato SBEs may not reflect the functionality of all fruit SBEs, but it would produce fundamental knowledge and expand our understanding of species-, organ- and developmental-specific regulations of the core starch biosynthetic enzymes.

\section{Conclusion}

Numerous studies on Arabidopsis and cereal crops have advanced our understanding of starch biosynthesis in leaf and endosperm, and this knowledge has been applied to starch quality improvement in agronomical crops. On the contrary, the functions of starch in diverse horticultural crops are poorly understood, but it may play an essential role in their postharvest quality.

SBEs largely determine starch composition and function (Figure S1), and there are three major classes of SBEs across cereal and horticultural crops (Fig. 1A). Compared to the well-studied SBE1 and SBE2, the function of the emerging SBE3 isoform in horticultural crops remains unknown (Fig. 1B). Although SBE3 has less invariant catalytic residues compared to SBE1 and SBE2 (Fig. 2), the gene structure of the SBE3 is highly conserved (Figure S2) and as is the protein secondary structure, including the critical CBM48 module (Figure S3). A unique coiled-coil region may provide SBE3 with a distinctive role in starch metabolism as an 'accessory protein' through forming protein complexes with core starch biosynthetic enzymes.

SBEs in leafy greens, tubers and roots, and fruits show divergent transcriptional patterns during organ 
development (Figs. 4, 5, and 6). The activity of SBEs may influence postharvest quality of these crops, influencing starch digestibility to sugars and hence its ability to serve as an energy source during storage, thereby affecting shelf-life. The proportion of sugars affects tissue osmotic properties, and if sugars levels are optimal at the crucial stage of postharvest life, this may reduce wilting, thereby boosting the visual appeal of leafy greens. Upon consumption, the proportion of sugars available in fruit vs. that used for respiration, or that remaining as starch, could influence taste, i.e., sweetness and nutritional attributes. Therefore, modulation of SBEs in major edible organs of these produces could test these hypotheses, and broaden our understanding of tissue- and species-specific starch metabolism, and potentially improve the postharvest attributes of several horticultural crops.

\begin{abstract}
Abbreviations
AM: Amylose; AP: Amylopectin; AM/AP: Amylose-to-amylopectin ratio; AGPase: ADPglucose pyrophosphorylase; CBM: Carbohydrate binding module; CIS: Cold induced sweetening; GBSS: Granule bound starch synthase; GI: Glycemic index; ISA: Isoamylase; PHO: Starch phosphorylase; PTST: Protein targeting to starch; RS: Resistant starch; SBE: Starch branching enzyme; SS: Starch synthase; StVInv: Solanum tuberosum vacuolar invertase; TSS: Total soluble solids.
\end{abstract}

\section{Supplementary Information}

The online version contains supplementary material available at https://doi. org/10.1186/s12870-021-03253-6.

Additional file 1: Figure S1. Mode of action of the starch branching enzymes (SBEs). Figure S2. Starch branching enzyme (SBE) gene structure in select horticultural crops. Figure S3. Protein domain of starch branching enzymes (SBEs) in select horticultural crops and Arabidopsis thaliana. Figure S4. Predicted cis-elements of the $2 \mathrm{~Kb}$ upstream region of the SBE coding sequences. Figure S5. Predicted protein-protein interaction 'STRING' networks of selected SBE proteins. Figure S6. Correlation between starch content and respiration in diverse ripening produce.

Additional file 2: Table S1. SBE expression, starch and sugar content, relative levels of amylopectin (AP) and amylose (AM) in various species. Table S2. STRING analyses of potential SBE-protein interactions. Table S3. Starch content and respiration data in various ripening produce.

\section{Acknowledgements}

JY thanks the Paulden F. \& Dorathea Knowles Scholarship, a UC Davis Horticulture \& Agronomy Graduate Group Scholarship, and the Henry A. Jastro Graduate Research Award for research support of his Master's degree. KW thanks the UC Davis's Provost Undergraduate Fellowship for funding to examine the role of starch in horticultural crops. DB acknowledges support by USDA Hatch Project CA-D-PLS-2404-H.

\section{Authors' contributions}

$J Y$ conceived the work, performed the bioinformatics meta-analysis, analyzed and interpreted the data, and drafted the manuscript. KW assisted JY with bioinformatics analysis and data compilation. DB directed the work, assisted with data analysis and interpretation, advised on writing, and edited drafts of the manuscript. The author(s) read and approved the final manuscript.

\section{Funding}

This work was supported by the California Potato Research Advisory Board; USDA Hatch Project CA-D-PLS-2404-H; and UC Davis's Provost Undergraduate
Fellowship. Funding agencies were not involved in the experimental design, nor did they carry out the research, collect or analyse the data, or write the manuscript.

\section{Availability of data and materials}

All data used in this manuscript is included in the Supplementary Files.

\section{Declarations}

Ethics approval and consent to participate

Not applicable.

Consent for publication

Not applicable.

\section{Competing interests}

The authors declare no competing interests.

\section{Author details}

${ }^{1}$ Department of Plant Sciences, University of California, One Shields Avenue, Davis, CA 95616, USA. ${ }^{2}$ Graduate Group of Horticulture \& Agronomy, University of California, Davis, CA 95616, USA. ${ }^{3}$ Present Address: Institute of Plant and Food Science, Department of Biology, School of Life Sciences, Southern University of Science and Technology, Shenzhen 518055, PR China.

Received: 31 May 2021 Accepted: 8 October 2021

Published online: 21 October 2021

\section{References}

1. Von Baeyer E. The development and history of horticulture. In: UNESCO, editor. World environmental history. United Kingdom: UNESCO Encyclopedia of Life Support Systems; 2010.

2. Tiwari AK, Nigam VK. Chapter 4 - Recent bio-processing technologies for value added horticultural products. In: Shukla P, editor. Applied microbiology and bioengineering. Cambridge: Academic Press; 2019. p. 57-67.

3. Gaur RK, Verma RK, Khurana SMP. Chapter 2 - Genetic engineering of horticultural crops: present and future. In: Rout GR, Peter KV, editors. Genetic engineering of horticultural crops. Cambridge: Academic Press; 2018. p. 23-46.

4. Sillitoe P. Horticultural societies. In: Wright JD, editor. International encyclopedia of the social \& behavioral sciences (second edition). Oxford: Elsevier; 2015. p. 202-7.

5. Shipman EN, Yu J, Zhou J, Albornoz K, Beckles DM. Can gene editing reduce postharvest waste and loss of fruit, vegetables, and ornamentals? Hortic Res. 2021;8(1):1.

6. Webb L, Darbyshire R, Goodwin I. Climate change: horticulture. In: Encyclopedia of agriculture and food systems, vol. 2. Amsterdam: Elsevier Inc.; 2014. p. 266-83.

7. Imahori Y. Chapter 14 - Role of ascorbate peroxidase in postharvest treatments of horticultural crops. In: Ahmad P, editor. Oxidative damage to plants. San Diego: Academic; 2014. p. 425-51.

8. Vicente AR, Manganaris GA, Sozzi GO, Crisosto $\mathrm{CH}$. Nutritional quality of fruits and vegetables. In: Florkowski WJ, Shewfelt RL, Brueckner B, Prussia SE, editors. Postharvest handling: a systems approach. Oxford: Elsevier-Academic; 2009. p. 57-106.

9. Beckles DM, Thitisaksakul M. Use of biotechnology to engineer starch in cereals. In: Encyclopedia of biotechnology in agriculture and food: Taylor \& Francis; 2014. https://doi.org/10.1081/E-EBAF-120051354.

10. Tetlow IJ, Morell MK, Emes MJ. Recent developments in understanding the regulation of starch metabolism in higher plants. J Exp Bot. 2004:55(406):2131-45.

11. Hong Y, Liu GD, Gu ZB. Recent advances of starch-based excipients used in extended-release tablets: a review. Drug Deliv. 2016;23(1):12-20.

12. Ochubiojo EM, Rodrigues A. Starch: from food to medicine. In: Valdez B, editor. Scientific, health and social aspects of the food industry. Rijeka: InTech; 2012. p. 355-80. 
13. Eliasson A-C. Starch in food- structure, function and application. Cambridge: CRC Press; 2004.

14. Marichelvam MK, Jawaid M, Asim M. Corn and rice starch-based bioplastics as alternative packaging materials. Fibers. 2019;7(4):32.

15. Martin C, Smith AM. Starch biosynthesis. Plant Cell. 1995;7(7):971-85.

16. Dong SY, Beckles DM. Dynamic changes in the starch-sugar interconversion within plant source and sink tissues promote a better abiotic stress response. J Plant Physiol. 2019;234:80-93.

17. Smith AM, Zeeman SC. Starch: a flexible, adaptable carbon store coupled to plant growth. Annu Rev Plant Biol. 2020;71(1):217-45.

18. Thalmann M, Santelia D. Starch as a determinant of plant fitness under abiotic stress. New Phytol. 2017;214(3):943-51.

19. MacNeill GJ, Mehrpouyan S, Minow MAA, Patterson JA, Tetlow IJ, Emes MJ. Starch as a source, starch as a sink: the bifunctional role of starch in carbon allocation. J Exp Bot. 2017;68(16):4433-53.

20. Lloyd JR, Kossmann J. Transitory and storage starch metabolism: two sides of the same coin? Curr Opin Biotechnol. 2015;32:143-8.

21. Zeeman SC, Smith SM, Smith AM. The diurnal metabolism of leaf starch. Biochem J. 2007;401:13-28.

22. Smirnova J, Fernie AR, Steup M. Starch degradation. In: Nakamura Y, editor. Starch. Tokyo: Springer; 2015. p. 239-90.

23. Sulpice R, Pyl ET, Ishihara H, Trenkamp S, Steinfath M, Witucka-Wall H, et al. Starch as a major integrator in the regulation of plant growth. $P$ Natl Acad Sci USA. 2009:106(25):10348-53.

24. Luengwilai K, Beckles DM. Structural investigations and morphology of tomato fruit starch. J Agric Food Chem. 2009;57(1):282-91.

25. Luengwilai K, Beckles DM. Starch granules in tomato fruit show a complex pattern of degradation. J Agric Food Chem. 2009;57(18):8480-7.

26. Kader AA. Postharvest biology and technology: an overview. In: Kader AA, editor. Postharvest technology of horticultural crops. Oakland: University of California, Agriculture and Natural Resources; 2002. p. 39-48.

27. Roch L, Prigent S, Klose H, Cakpo CB, Beauvoit B, Deborde C, et al. Biomass composition explains fruit relative growth rate and discriminates climacteric from non-climacteric species. J Exp Bot. 2020;71(19):5823-36.

28. Pfister B, Zeeman SC. Formation of starch in plant cells. Cell Mol Life Sci. 2016;73(14):2781-807.

29. Hizukuri S. Polymodal distribution of the chain lengths of amylopectins, and its significance. Carbohydr Res. 1986;147(2):342-7.

30. Magallanes-Cruz PA, Flores-Silva PC, Bello-Perez LA. Starch structure influences its digestibility: a review. J Food Sci. 2017;82(9):2016-23.

31. Tetlow IJ, Bertoft E. A review of starch biosynthesis in relation to the building block-backbone model. Int J Mol Sci. 2020;21 (19):7011.

32. Ai Y, Jane J-L. Chapter 3 - Understanding starch structure and functionality. In: Sjöö M, Nilsson L, editors. Starch in food (second edition). Sawston: Woodhead Publishing; 2018. p. 151-78.

33. Robyt JF. Starch: structure, properties, chemistry, and enzymology. In: Fraser-Reid BO, Tatsuta K, Thiem J, editors. Glycoscience: chemistry and chemical biology. Berlin, Heidelberg: Springer Berlin Heidelberg; 2008. p. 1437-72.

34. Hovenkamp-Hermelink JHM, De Vries JN, Adamse P, Jacobsen E, Witholt B, Feenstra WJ. Rapid estimation of the amylose/amylopectin ratio in small amounts of tuber and leaf tissue of the potato. Potato Res, 1988;31(2):241-6.

35. Lloyd JR, Kötting O. Starch biosynthesis and degradation in plants. In: eLS. Hoboken: Wiley; 2016. p. 1-10.

36. Zeeman SC, Kossmann J, Smith AM. Starch: its metabolism, evolution, and biotechnological modification in plants. Annu Rev Plant Biol. 2010;61:209-34.

37. Beckles DM, Craig J, Smith AM. ADP-glucose pyrophosphorylase is located in the plastid in developing tomato fruit. Plant Physiol. 2001;126(1):261-6.

38. Beckles DM, Smith AM, ap Rees T. A cytosolic ADP-glucose pyrophosphorylase is a feature of graminaceous endosperms, but not of other starch-storing organs. Plant Physiol. 2001;125(2):818-27.

39. Leterrier M, Holappa LD, Broglie KE, Beckles DM. Cloning, characterisation and comparative analysis of a starch synthase IV gene in wheat: functional and evolutionary implications. BMC Plant Biol. 2008;8(1):1-21.

40. Tetlow IJ, Emes MJ. A review of starch-branching enzymes and their role in amylopectin biosynthesis. IUBMB Life. 2014;66(8):546-58.
41. Pfister B, Lu KJ, Eicke S, Feil R, Lunn JE, Streb S, et al. Genetic evidence that chain length and branch point distributions are linked determinants of starch granule formation in Arabidopsis. Plant Physiol. 2014;165(4):1457-74.

42. Sestili F, Janni M, Doherty A, Botticella E, D'Ovidio R, Masci S, et al. Increasing the amylose content of durum wheat through silencing of the SBEllagenes. BMC Plant Biol. 2010;10(1):144.

43. Regina A, Kosar-Hashemi B, Ling S, Li ZY, Rahman S, Morell M. Control of starch branching in barley defined through differential RNAi suppression of starch branching enzyme lla and Ilb. J Exp Bot. 2010;61(5):1469-82.

44. Wang J, Hu P, Chen ZC, Liu QQ, Wei CX. Progress in high-amylose cereal crops through inactivation of starch branching enzymes. Front Plant Sci. 2017:8:469.

45. Qu J, Xu S, Zhang Z, Chen G, Zhong Y, Liu L, et al. Evolutionary, structural and expression analysis of core genes involved in starch synthesis. Sci Rep-Uk. 2018;8(1):1-6.

46. Wolfe KH, Gouy M, Yang YW, Sharp PM, Li WH. Date of the monocotdicot divergence estimated from chloroplast DNA sequence data. P Natl Acad Sci USA. 1989:86(16):6201-5.

47. Rahman S, Regina A, Li ZY, Mukai Y, Yamamoto M, Kosar-Hashemi B, et al. Comparison of starch-branching enzyme genes reveals evolutionary relationships among isoforms. Characterization of a gene for starchbranching enzyme lla from the wheat D genome donor Aegilops tauschii. Plant Physiol. 2001;125(3):1314-24.

48. Blauth SL, Yao Y, Klucinec JD, Shannon JC, Thompson DB, Guilitinan MJ. Identification of mutator insertional mutants of starch-branching enzyme 2a in corn. Plant Physiol. 2001;125(3):1396-405.

49. Dumez S, Wattebled F, Dauvillee D, Delvalle D, Planchot V, Ball SG, et al. Mutants of Arabidopsis lacking starch branching enzyme II substitute plastidial starch synthesis by cytoplasmic maltose accumulation. Plant Cell. 2006;18(10):2694-709.

50. Larsson CT, Khoshnoodi J, Ek B, Rask L, Larsson H. Molecular cloning and characterization of starch-branching enzyme II from potato. Plant Mol Biol. 1998;37(3):505-11.

51. Nakayama S, Nakamura Y. Purification and some properties of starch branching enzyme (Q-enzyme) from tuberous root of sweet potato. Physiol Plantarum. 1994;91(4):763-9.

52. Curtolo M, Cristofani-Yaly M, Gazaffi R, Takita MA, Figueira A, Machado MA. QTL mapping for fruit quality in Citrus using DArTseq markers. BMC Genomics. 2017;18(1):1-6.

53. Ohta S, Endo T, Shimada T, Fujii H, Shimizu T, Kita M, et al. Construction of genetic linkage map and graphical genotyping of pseudo-backcrossed F-2 (BC2') progeny to introduce a CTV resistance from Poncirus trifoliata (L.) Raf. into Citrus by introgression breeding. Tree Genet Genomes. 2015:11(1):797.

54. Fernandez-Pozo N, Menda N, Edwards JD, Saha S, Tecle IY, Strickler SR, et al. The Sol Genomics Network (SGN)-from genotype to phenotype to breeding. Nucleic Acids Res. 2015;43(D1):D1036-41.

55. Sultana N, Menzel G, Heitkam T, Kojima KK, Bao WD, Serce S. Bioinformatic and molecular analysis of satellite repeat diversity in Vaccinium genomes. Genes-Basel. 2020;11(5):527.

56. Clepet $C$, Joobeur $T$, Zheng $Y$, Jublot $D$, Huang MY, Truniger $V$, et al. Analysis of expressed sequence tags generated from full-length enriched cDNA libraries of melon. BMC Genomics. 2011;12(1):1-2.

57. Zheng Y, Wu S, Bai Y, Sun HH, Jiao C, Guo SG, et al. Cucurbit Genomics Database (CuGenDB): a central portal for comparative and functional genomics of cucurbit crops. Nucleic Acids Res. 2019:47(D1):D1128-36.

58. Ming R, VanBuren R, Wai CM, Tang HB, Schatz MC, Bowers JE, et al. The pineapple genome and the evolution of CAM photosynthesis. Nat Genet. 2015:47(12):1435-+.

59. Ming R, Wai CM, Guyot R. Pineapple genome: a reference for monocots and CAM photosynthesis. Trends Genet. 2016;32(11):690-6.

60. Collins K, Zhao K, Jiao C, et al. SpinachBase: a central portal for spinach genomics. Database (Oxford). 2019;2019:baz072:1-8. https://doi.org/10, 1093/database/baz072.

61. Kanehisa M, Goto S. KEGG: Kyoto encyclopedia of genes and genomes. Nucleic Acids Res. 2000;28(1):27-30.

62. Yates AD, Achuthan P, Akanni W, Allen J, Allen J, Alvarez-Jarreta J, et al. Ensembl 2020. Nucleic Acids Res. 2020:48(D1):D682-8. 
63. Boyer CD, Preiss J.Evidencefor independent genetic-control of starch branching enzymes from developing maize kernels. Plant Physiol. 1978;61(4):39.

64. Miao H, Sun P, Liu Q, Liu J, Jia C, Zhao D, et al. Molecular identification of the key starch branching enzyme-encoding gene SBE2.3 and its interacting transcription factors in banana fruits. Hortic Res. 2020;7(1):101.

65. Feng L, Fawaz R, Hovde S, Gilbert L, Chiou J, Geiger JH. Crystal structures of Escherichia coli branching enzyme in complex with linear oligosaccharides. Biochemistry. 2015;54(40):6207-18.

66. Abad MC, Binderup K, Rios-Steiner J, Arni RK, Preiss J, Geiger JH. The X-ray crystallographic structure of Escherichia coli branching enzyme. J Biol Chem. 2002;277(44):42164-70.

67. Kuriki T. Analysis of the active center of branching enzyme II from maize endosperm. J Protein Chem. 1996;15(3):305-13.

68. Jespersen HM, Macgregor EA, Sierks MR, Svensson B. Comparison of the domain-level organization of starch hydrolases and related enzymes. Biochem J. 1991;280:51-5.

69. MacGregor EA, Janecek S, Svensson B. Relationship of sequence and structure to specificity in the alpha-amylase family of enzymes. Biochim Biophys Acta. 2001;1546(1):1-20.

70. Crooks GE, Hon G, Chandonia JM, Brenner SE. WebLogo: a sequence logo generator. Genome Res. 2004;14(6):1 188-90.

71. Janecek S, Svensson B, MacGregor EA. Structural and evolutionary aspects of two families of non-catalytic domains present in starch and glycogen binding proteins from microbes, plants and animals. Enzyme Microb Technol. 2011:49(5):429-40.

72. Wang XC, Xue L, Sun JQ, Zuo JR. The Arabidopsis BE1 gene, encoding a putative glycoside hydrolase localized in plastids, plays crucial roles during embryogenesis and carbohydrate metabolism. J Integr Plant Biol. 2010;52(3):273-88

73. Zhang JX, Yang J, Zhang T, Yang QH, Gao HR, Cheng HM, et al. Arabidopsis thaliana branching enzyme 1 is essential for amylopectin biosynthesis and cesium tolerance. J Plant Physiol. 2020;252:153208.

74. Lu KJ, Pfister B, Jenny C, Eicke S, Zeeman SC. Distinct functions of STARCH SYNTHASE 4 domains in starch granule formation. Plant Physiol. 2018;176(1):566-81.

75. Wang W, Wei XJ, Jiao GA, Chen WQ, Wu YW, Sheng ZH, et al. GBSSBINDING PROTEIN, encoding a CBM48 domain-containing protein, affects rice quality and yield. J Integr Plant Biol. 2020;62(7):948-66.

76. Tetlow IJ, Beisel KG, Cameron S, Makhmoudova A, Liu F, Bresolin NS, et al. Analysis of protein complexes in wheat amyloplasts reveals functional interactions among starch biosynthetic enzymes. Plant Physiol. 2008;146(4):1878-91.

77. Guan HP, Keeling PL. Starch biosynthesis: understanding the functions and interactions of multiple isozymes of starch synthase and branching enzyme. Trends Glycosci Glycotechnol. 1998;10(54):307-19.

78. He S, Hao X, Wang S, Zhou W, Ma Q, Lu X, et al. A newly-identified inactive starch synthase simultaneously regulates starch synthesis and carbon allocation in storage roots of cassava (Manihot esculenta Crantz). bioRxiv. 2020:2020.2003.2025.006957.

79. Makhmoudova A, Williams D, Brewer D, Massey S, Patterson J, Silva $A$, et al. Identification of multiple phosphorylation sites on maize endosperm starch branching enzyme llb, a key enzyme in amylopectin biosynthesis. J Biol Chem. 2014;289(13):9233-46.

80. Graf A, Smith AM. Starch and the clock: the dark side of plant productivity. Trends Plant Sci. 2011;16(3):169-75.

81. Baguma Y, Sun C, Ahlandsberg S, Mutisya J, Palmqvist S, Rubaihayo $\mathrm{PR}$, et al. Expression patterns of the gene encoding starch branching enzyme II in the storage roots of cassava (Manihot esculenta Crantz). Plant Sci. 2003;164(5):833-9.

82. Blasing OE, Gibon Y, Gunther M, Hohne M, Morcuende R, Osuna D, et al. Sugars and circadian regulation make major contributions to the global regulation of diurnal gene expression in Arabidopsis. Plant Cell. 2005;17(12):3257-81.

83. Mukherjee S, Liu AH, Deol KK, Kulichikhin K, Stasolla C, Brule-Babel A, et al. Transcriptional coordination and abscisic acid mediated regulation of sucrose transport and sucrose-to-starch metabolism related genes during grain filling in wheat (Triticum aestivum L.). Plant Sci. 2015;240:143-60.

84. Cai $Y$, Xie DL, Wang ZY, Hong MM. Interaction of rice bZIP protein REB with the $5^{\prime}$-upstream region of both rice sbe1 gene and waxy gene. Chin Sci Bull. 2002;47(4):310-4.
85. Huang HH, Xie SD, Xiao QL, Wei B, Zheng LJ, Wang YB, et al. Sucrose and $A B A$ regulate starch biosynthesis in maize through a novel transcription factor, ZmEREB156. Sci Rep-Uk. 2016;6(1):1-2.

86. Wang JC, Xu H, Zhu Y, Liu QQ, Cai XL. OsbZIP58, a basic leucine zipper transcription factor, regulates starch biosynthesis in rice endosperm. J Exp Bot. 2013;64(11):3453-66.

87. Lopez-Gonzalez C, Juarez-Colunga S, Morales-Elias NC, Tiessen A. Exploring regulatory networks in plants: transcription factors of starch metabolism. PeerJ. 2019;7:e6841.

88. Li HT, Gidley MJ, Dhital S. High-amylose starches to bridge the "Fiber Gap": development, structure, and nutritional functionality. Compr Rev Food Sci Food Saf. 2019;18(2):362-79.

89. Li HY, Prakash S, Nicholson TM, Fitzgerald MA, Gilbert RG. The importance of amylose and amylopectin fine structure for textural properties of cooked rice grains. Food Chem. 2016;196:702-11.

90. Nugent AP. Health properties of resistant starch. Nutr Bull. 2005;30(1):27-54.

91. Tan HZ, Li ZG, Tan B. Starch noodles: history, classification, materials, processing, structure, nutrition, quality evaluating and improving. Food Res Int. 2009:42(5-6):551-76.

92. Beckles DM, Thitisaksakul M. How environmental stress affects starch composition and functionality in cereal endosperm. Starch-Starke. 2014;66(1-2):58-71.

93. Yahia EM, Carrillo-López A, Bello-Perez LA. Carbohydrates. In: Yahia EM, editor. Postharvest physiology and biochemistry of fruits and vegetables. Sawston: Woodhead Publishing; 2019. p. 175-205.

94. Smith RB, Lougheed EC, Franklin EW, McMillan I. The starch iodine test for determining stage of maturation in apples. Can J Plant Sci. 1979;59(3):725-35.

95. Blankenship SM, Ellsworth DD, Powell RL. A ripening index for banana fruit based on starch content. HortTechnology. 1993;3(3):338-9. https:// doi.org/10.21273/HORTTECH.3.3.338.

96. Moreno JL, Tran T, Cantero-Tubilla B, Lopez-Lopez K, Lavalle LABL, Dufour D. Physicochemical and physiological changes during the ripening of Banana (Musaceae) fruit grown in Colombia. Int J Food Sci Technol. 2021;56(3):1171-83.

97. Kumar S, Thakur KS. Effect of 1-methylcyclopropene (1-MCP) application and periodic cold storage on ripening of "Bartlett" pear during ambient shelf life periods. J Food Process Preserv. 2020;44(6):e14467.

98. Carrin ME, Ceci LN, Lozano JE. Characterization of starch in apple juice and its degradation by amylases. Food Chem. 2004;87(2):173-8.

99. Kwok SCM, Chan HT Jr, Nakayama TOM, Brekke JE. Passion fruit starch and effect on juice viscosity. J Food Sci. 1974;39(3):431-3.

100. Barrett DM, Beaulieu JC, Shewfelt R. Color, flavor, texture, and nutritional quality of fresh-cut fruits and vegetables: desirable levels, instrumental and sensory measurement, and the effects of processing. Crit Rev Food Sci. 2010:50(5):369-89.

101. Sams CE. Preharvest factors affecting postharvest texture. Postharvest Biol Technol. 1999:15(3):249-54.

102. Sharkey TD. Understanding carbon partitioning and its role in determining plant growth. Plant Cell Environ. 2015:38(10):1963-4.

103. Izumi M, Nakamura S, Li N. Autophagic Turnover of Chloroplasts: Its Roles and Regulatory Mechanisms in Response to Sugar Starvation. Front Plant Sci. 2019;10:280. https://doi.org/10.3389/fpls.2019.00280.

104. Orzechowski S. Starch metabolism in leaves. Acta Biochim Pol. 2008;55(3):435-45.

105. Dinges JR, Colleoni C, James MG, Myers AM. Mutational analysis of the pullulanase-type debranching enzyme of maize indicates multiple functions in starch metabolism. Plant Cell. 2003;15(3):666-80.

106. Edwards D, Ehret D, Jolliffe P. Temporal variations of starch and mass in greenhouse tomato leaves under $\mathrm{CO} 2$ enrichment. Can J Plant Sci. 2011;91(1):167-77.

107. Fernandez $\mathrm{O}$, Ishihara $\mathrm{H}$, George GM, Mengin V, Flis A, Sumner D, et al. Leaf starch turnover occurs in long days and in falling light at the end of the day. Plant Physiol. 2017;174(4):2199-212.

108. Gent MPN. Effect of irradiance and temperature on composition of spinach. Hortscience. 2016;51(2):133-40.

109. Smith SM, Fulton DC, Chia T, Thorneycroft D, Chapple A, Dunstan H, et al. Diurnal changes in the transcriptome encoding enzymes of starch metabolism provide evidence for both transcriptional and 
posttranscriptional regulation of starch metabolism in arabidopsis leaves. Plant Physiol. 2004;136(1):2687-99.

110. Zhu F, Bertoft E, Wang Y, Emes M, Tetlow I, Seetharaman K. Structure of Arabidopsis leaf starch is markedly altered following nocturnal degradation. Carbohyd Polym. 2015;117:1002-13.

111. Finger FL, Endres L, Mosquim PR, Puiatti M. Physiological changes during postharvest senescence of broccoli. Pesqui Agropecu Bras. 1999;34(9):1565-9.

112. Koukounaras A, Bantis F, Karatolos N, Melissas C, Vezyroglou A. Influence of pre-harvest factors on postharvest quality of fresh-cut and baby leafy vegetables. Agronomy. 2020;10(2):172.

113. Mahajan PV, Caleb OJ, Singh Z, Watkins CB, Geyer M. Postharvest treatments of fresh produce. Philos Trans A Math Phys Eng Sci. 2014;372(2017):20130309.

114. Kim J. Sugar metabolism as input signals and fuel for leaf senescence. Genes Genomics. 2019:41(7):737-46.

115. Solomos T. Respiration and energy metabolism in senescing plant tissues. In: Lieberman M, editor. Post-harvest physiology and crop preservation. Boston: Springer US; 1983. p. 61-98.

116. Dong SY, Zhang FL, Beckles DM. A cytosolic protein kinase STY46 in Arabidopsis thaliana is involved in plant growth and abiotic stress response. Plants-Basel. 2020;9(1):57.

117. Clarkson GJJ, Rothwell S, Taylor G. End of day harvest extends shelf life Hortscience. 2005:40:1431-5.

118. Noichinda S, Bodhipadma K, Mahamontri C, Narongruk T, Ketsa S. Light during storage prevents loss of ascorbic acid, and increases glucose and fructose levels in Chinese kale (Brassica oleracea var. alboglabra). Postharvest Biol Technol. 2007:44(3):312-5.

119. Bárcena A, Martínez G, Costa L. Low intensity light treatment improves purple kale (Brassica oleracea var. sabellica) postharvest preservation at room temperature. Heliyon. 2019;5(9):e02467.

120. Chen Y, Fanourakis D, Tsaniklidis G, Aliniaeifard S, Yang Q, Li T. Low UVA intensity during cultivation improves the lettuce shelf-life, an effect that is not sustained at higher intensity. Postharvest Biol Technol. 2021:172:111376.

121. Min Q, Marcelis LFM, Nicole CCS, Woltering EJ. High light intensity applied shortly before harvest improves lettuce nutritional quality and extends the shelf life. Front Plant Sci. 2021;12(76):615355.

122. Kou LP, Luo YG, Park E, Turner ER, Barczak A, Jurick WM. Temperature abuse timing affects the rate of quality deterioration of commercially packaged ready-to-eat baby spinach. Part I: sensory analysis and selected quality attributes. Postharvest Biol Technol. 2014;91:96-103.

123. Yusof NL, Wadso L, Rasmusson AG, Galindo FG. Influence of vacuum impregnation with different substances on the metabolic heat production and sugar metabolism of spinach leaves. Food Bioprocess Technol. 2017;10(10):1907-17.

124. Zhang WY, Gu JF, Wang ZQ, Wei CX, Yang JC, Zhang JH. Comparison of structural and functional properties of wheat starch under different soil drought conditions. Sci Rep-Uk. 2017;7(1):1-8.

125. Ortiz-Marchena MI, Albi T, Lucas-Reina E, Romero-Campero FJ, Said FE, Cano B, et al. Photoperiodic control of carbon distribution during the floral transition in Arabidopsis thaliana. FEBS J. 2014:281:589.

126. Colussi R, Singh J, Kaur L, Zavareze ED, Dias ARG, Stewart RB, et al. Microstructural characteristics and gastro-small intestinal digestion in vitro of potato starch: effects of refrigerated storage and reheating in microwave. Food Chem. 2017;226:171-8

127. Ludwig DS, Majzoub JA, Al-Zahrani A, Dallal GE, Blanco I, Roberts SB. High glycemic index foods, overeating, and obesity. Pediatrics. 1999;103(3):e26.

128. Birt DF, Boylston T, Hendrich S, Jane JL, Hollis J, Li L, et al. Resistant starch: promise for improving human health. Adv Nutr. 2013:4(6):587-601.

129. Park SH, Na Y, Kim J, Kang SD, Park KH. Properties and applications of starch modifying enzymes for use in the baking industry. Food Sci Biotechnol. 2018;27(2):299-312.

130. Tuncel A, Corbin KR, Ahn-Jarvis J, Harris S, Hawkins E, Smedley MA et al. Cas9-mediated mutagenesis of potato starch-branching enzymes generates a range of tuber starch phenotypes. Plant Biotechnol J. 2019;17(12):2259-71.

131. Asai H, Abe N, Matsushima R, Crofts N, Oitome NF, Nakamura Y, et al. Deficiencies in both starch synthase Illa and branching enzyme llb lead to a significant increase in amylose in SSIlla-inactive japonica rice seeds. J Exp Bot. 2014;65(18):5497-507.

132. Butardo VM, Fitzgerald MA, Bird AR, Gidley MJ, Flanagan BM, Larroque $\mathrm{O}$, et al. Impact of down-regulation of starch branching enzyme Illb in rice by artificial microRNA-and hairpin RNA-mediated RNA silencing. J Exp Bot. 2011;62(14):4927-41.

133. Gao M, Fisher DK, Kim KN, Shannon JC, Guiltinan MJ. Independent genetic control of maize starch-branching enzymes lla and Ilb - isolation and characterization of a Sbe2a cDNA. Plant Physiol. 1997;114(1):69-78.

134. Hazard B, Zhang XQ, Colasuonno P, Uauy C, Beckles DM, Dubcovsky J. Induced mutations in the starch branching enzyme II (SBEII) genes increase amylose and resistant starch content in durum wheat. Crop Sci. 2012;52(4):1754-66.

135. Safford R, Jobling SA, Sidebottom CM, Westcott RJ, Cooke D, Tober KJ, et al. Consequences of antisense RNA inhibition of starch branching enzyme activity on properties of potato starch. Carbohyd Polym. 1998:35(3-4):155-68.

136. Tanaka N, Fujita N, Nishi A, Satoh H, Hosaka Y, Ugaki M, et al. The structure of starch can be manipulated by changing the expression levels of starch branching enzyme llb in rice endosperm. Plant Biotechnol J. 2004;2(6):507-16.

137. Zhou WZ, Zhao SS, He ST, Ma QX, Lu XL, Hao XM, et al. Production of very-high-amylose cassava by post-transcriptional silencing of branching enzyme genes. J Integr Plant Biol. 2020;62(6):832-46.

138. Wei CX, Xu B, Qin FL, Yu HG, Chen C, Meng XL, et al. C-type starch from high-amylose rice resistant starch granules modified by antisense RNA inhibition of starch branching enzyme. J Agric Food Chem. 2010;58(12):7383-8

139. Xia H, Yandeau-Nelson M, Thompson DB, Guiltinan MJ. Deficiency of maize starch-branching enzyme I results in altered starch fine structure, decreased digestibility and reduced coleoptile growth during germination. BMC Plant Biol. 2011;11:95.

140. Zhao X, Jayarathna S, Turesson H, Falt AS, Nestor G, Gonzalez MN, et al. Amylose starch with no detectable branching developed through DNA-free CRISPR-Cas9 mediated mutagenesis of two starch branching enzymes in potato. Sci Rep-Uk. 2021;11(1):1-3.

141. Jobling SA, Schwall GP, Westcott RJ, Sidebottom CM, Debet M, Gidley $\mathrm{MJ}$, et al. A minor form of starch branching enzyme in potato (Solanum tuberosum L.) tubers has a major effect on starch structure: cloning and characterisation of multiple forms of SBE A. Plant J. 1999;18(2):163-71.

142. Schwall GP, Safford R, Westcott RJ, Jeffcoat R, Tayal A, Shi YC, et al. Production of very-high-amylose potato starch by inhibition of SBE A and B. Nat Biotechnol. 2000;18(5):551-4.

143. Huang H, Luo Y, Huang Q, Tian Y, Li H, Hou X. Time course of starch biosynthesis enzymes activity and root tuber starch of four cassava cultivars. J Agric Stud. 2017;5(1):11.

144. Li YZ, Zhao JY, Wu SM, Fan XW, Luo XL, Chen BS. Characters related to higher starch accumulation in cassava storage roots. Sci Rep-Uk. 2016;6(1):1-7.

145. Ferreira SJ, Senning M, Sonnewald S, Kessling PM, Goldstein R, Sonnewald $U$. Comparative transcriptome analysis coupled to $X$-ray CT reveals sucrose supply and growth velocity as major determinants of potato tuber starch biosynthesis. BMC Genomics. 2010;11(1):1-7.

146. Lewis CE, Lancaster JE, Meredith P, Walker JRL. Starch metabolism during growth and storage of tubers of two New Zealand potato cultivars. N Z J Crop Hortic Sci. 1994;22(3):295-304.

147. Tai HH, Lague M, Thomson S, Aurousseau F, Neilson J, Murphy A, et al. Tuber transcriptome profiling of eight potato cultivars with different cold-induced sweetening responses to cold storage. Plant Physiol Biochem. 2020;146:163-76.

148. Amir J, Kahn V, Unterman M. Respiration, ATP level, and sugar accumulation in potato tubers during storage at $4^{\circ}$. Phytochemistry. 1977;16(10):1495-8.

149. Burton WG. The sugar balance in some British potato varieties during storage. II. The effects of tuber age, previous storage temperature, and intermittent refrigeration upon low-temperature sweetening. Potato Res. 1969;12(2):81-95.

150. Gökmen V, Palazoğlu TK. Acrylamide formation in foods during thermal processing with a focus on frying. Food Bioprocess Technol. 2008;1(1):35-42. 
151. Mottram DS, Wedzicha BL, Dodson AT. Acrylamide is formed in the Maillard reaction. Nature. 2002;419(6906):448-9.

152. Cochrane MP, Duffus CM, Allison MJ, Mackay GR. Amylolytic activity in stored potato-tubers. 2. The effect of low-temperature storage on the activities of alpha-amylase and beta-amylase and alpha-glucosidase in potato-tubers. Potato Res. 1991;34(4):333-41.

153. Bhaskar PB, Wu L, Busse JS, Whitty BR, Hamernik AJ, Jansky SH, et al. Suppression of the vacuolar invertase gene prevents cold-induced sweetening in potato. Plant Physiol. 2010;154(2):939-48.

154. Jansky SH, Fajardo DA. Tuber starch amylose content is associated with cold-induced sweetening in potato. Food Sci Nutr. 2014;2(6):628-33.

155. Li D, Zhu F. Starch structure in developing kiwifruit. Int J Biol Macromol. 2018;120:1306-14.

156. Chervin C. Should starch metabolism be a key point of the climacteric vs. non-climacteric fruit definition? Front Plant Sci. 2020;11:931. https:// doi.org/10.3389/fpls.2020.609189.

157. Colombie S, Beauvoit B, Nazaret C, Benard C, Vercambre G, Le Gall S, et al. Respiration climacteric in tomato fruits elucidated by constraintbased modelling. New Phytol. 2017;213(4):1726-39.

158. Zhou J, Chen B, Albornoz K, Beckles DM. Postharvest handling induces changes in fruit DNA methylation status and is associated with alterations in fruit quality in tomato (Solanum lycopersicum L.). Sci HorticAmsterdam. 2021;283:110090.

159. Albornoz K, Cantwell MI, Zhang L, Beckles DM. Integrative analysis of postharvest chilling injury in cherry tomato fruit reveals contrapuntal spatio-temporal responses to ripening and cold stress. Sci Rep-Uk. 2019:9(1):1-4.

160. Garcia E, Lajolo FM. Starch transformation during Banana ripening: the amylase and glucosidase behavior. J Food Sci. 1988:53(4):1181-6.

161. Xiao YY, Kuang JF, Qi XN, Ye YJ, Wu ZX, Chen JY, et al. A comprehensive investigation of starch degradation process and identification of a transcriptional activator MabHLH6 during banana fruit ripening. Plant Biotechnol J. 2018;16(1):151-64.

162. Purgatto E, do Nascimento JRO, Lajolo FM, Cordenunsi BR. The onset of starch degradation during banana ripening is concomitant to changes in the content of free and conjugated forms of indole-3-acetic acid. J Plant Physiol. 2002;159(10):1105-11.

163. Lv JY, Bai L, Han XZ, Xu DL, Ding SY, Li CY, et al. Effects of 1-MCP treatment on sprouting and preservation of ginger rhizomes during storage at room temperature. Food Chem. 2021;349:129004.

164. Patel PR, Gol NB, Rao TVR. Physiochemical changes in sunberry (Physalis minima L.) fruit during growth and ripening. Fruits. 2011:66(1):37-46.

165. Thammawong M, Arakawa O. Starch degradation of detached apple fruit in relation to ripening and ethylene. J Jpn Soc Hortic Sci. 2007;76(4):345-50.

166. Ketsa S, Daengkanit T. Physiological changes during postharvest ripening of durian fruit (Durio zibethinus Murray). J Hortic Sci Biotechnol. 1998;73(5):575-7.
167. Marriott J, Robinson M, Karikari SK. Starch and sugar transformation during the ripening of plantains and bananas. J Sci Food Agric. 1981;32(10):1021-6.

168. Souleyre EJF, lannetta PPM, Ross HA, Hancock RD, Shepherd LVT, Viola R, et al. Starch metabolism in developing strawberry (Fragaria $x$ ananassa) fruits. Physiol Plantarum. 2004;121(3):369-76.

169. Yu MH, Olson LE, Salunkhe DK. Precursors of volatile components in tomato fruit. 1. Compositional changes during development. Phytochemistry. 1967;6(11):1457.

170. Nardozza S, Cooney J, Boldingh HL, Hewitt KG, Trower T, Jones D, et al. Phytohormone and transcriptomic analysis reveals endogenous cytokinins affect kiwifruit growth under restricted carbon supply. Metabolites. 2020;10(1):23.

171. Toal TW, Ron M, Gibson D, Kajala K, Splitt B, Johnson LS, et al. Regulation of root angle and gravitropism. G3 (Bethesda). 2018;8(12):3841-55.

172. Da LL, Liu Y, Yang JT, Tian T, She JJ, Ma XL, et al. AppleMDO: a multidimensional omics database for apple co-expression networks and chromatin states. Front Plant Sci. 2019;10:1333.

173. Magein $\mathrm{H}$, Leurquin D. Changes in amylose, amylopectin and total starch content in jonagold apple fruit during growth and maturation. Leuven: International Society for Horticultural Science (ISHS); 2000. p. 487-94.

174. Mohammed M, Bridgemohan P, Mohamed MS, Bridgemohan RS, Mohammed Z. Postharvest physiology and storage of golden apple (Spondias cytherea sonnerat or Spondias dulcis forst): a review. J Food Process Technol. 2017;8:12.

175. Miao HX, Sun PG, Liu WX, Xu BY, Jin ZQ. Identification of genes encoding granule-bound starch synthase involved in amylose metabolism in banana fruit. PLoS One. 2014;9(2):e88077.

176. Stitt M, Lunn J, Usadel B. Arabidopsis and primary photosynthetic metabolism - more than the icing on the cake. Plant J. 2010;61 (6):1067-91.

177. Seung D, Echevarria-Poza A, Steuernagel B, Smith AM. Natural polymorphisms in Arabidopsis result in wide variation or loss of the amylose component of starch. Plant Physiol. 2020;182(2):870-81.

178. Tarkowski LP, Van den Ende W. Cold tolerance triggered by soluble sugars: a multifaceted countermeasure. Front Plant Sci. 2015;6:203.

179. Bertin N, Genard M. Tomato quality as influenced by preharvest factors. Sci Hortic-Amsterdam. 2018;233:264-76.

\section{Publisher's Note}

Springer Nature remains neutral with regard to jurisdictional claims in published maps and institutional affiliations.
Ready to submit your research? Choose BMC and benefit from:

- fast, convenient online submission

- thorough peer review by experienced researchers in your field

- rapid publication on acceptance

- support for research data, including large and complex data types

- gold Open Access which fosters wider collaboration and increased citations

- maximum visibility for your research: over $100 \mathrm{M}$ website views per year

At BMC, research is always in progress.

Learn more biomedcentral.com/submissions 